\title{
A generations view on SDG - using the central role of maps
}

\author{
Markus Jobst ${ }^{\mathrm{a}, *}$, Georg Gartner ${ }^{\mathrm{b}}$ \\ ${ }^{a}$ Research Unit Cartography, Department of Geodesy and Geoinformation, Vienna University of Technology, \\ markus@jobstmedia.at \\ ${ }^{b}$ Research Unit Cartography, Department of Geodesy and Geoinformation, Vienna University of Technology,, \\ georg.gartner@tuwien.ac.at \\ * Corresponding author
}

\begin{abstract}
In 2019 the ICA commission on map production and geoinformation management, together with the research group of cartography of the Vienna University of Technology, some schools and the publisher Jobstmedia, have started an initiative to collect the generation's view on SDG and its expression with maps. The aim is a continuous edited book atlas in print and digital form, which illustrates the range of perspectives on the SDGs and their motivations for establishing a sustainable world (http://sdggeneration.cartography.at/).
\end{abstract}

Keywords: UN sustainable development goals, children cartography, expression with maps

\section{Introduction}

The UN sustainable development goals (SDG) become visible in many domains. Humans need to change their way of living in order to preserve environment and establish a better coexistence. A given time schedule and defined goals shall help to track changes. The discussions about SDG are becoming visible to children, students and experts of different domains, which creates specific views and cognitive imageries. All of them are important to achieve a consensual way of SDG implementation. A map drawing is one specific technique, which allows for the expression of thoughts (Pellier 2014). This access to cognitive imageries can be used by different ages, which is important for the long-term perspective of SDG. This paper describes an initiative that collects the generation's view on SDG and its expression with maps.

\section{Sustainable Development Goals (SDG) and their impact on generations}

The development of environment and society is a hot topic for decades (Sachs 2021). Scientists observe the impact of humans on earth, others investigate economic development or explore a negative impact of capitalism on our society. The first documented activities of SDG's go back to the United Nations Conference on the Human Environment in Stockholm in 1972 (Engström 1972), where the relationship between humans and their environment has been addressed. As result of the conference the global reflection about the balance of environmental protection and human development has been initiated. These fifty years of reflection have had their disappointments, but also instructive phases, which lead to a definition of seventeen goals with a set of controllable indicators. The up-and-downs in these fifty years were part of a public discussion. Thus society does

Figure 1: Sample of primary school statement

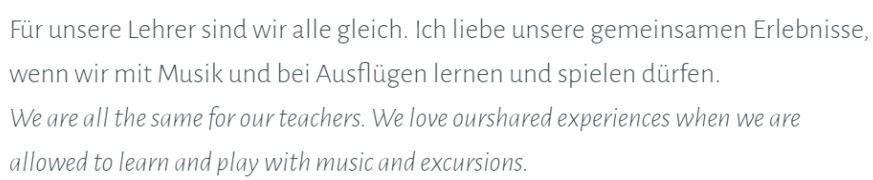

allowed to learn and play with music and excursions.

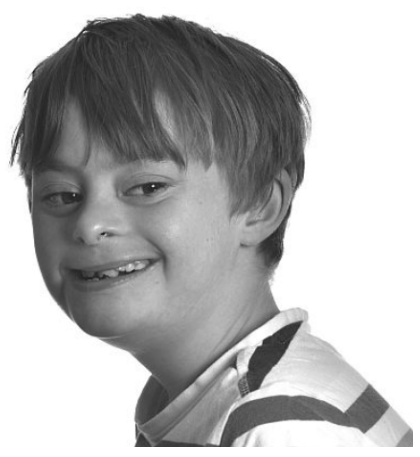


not always agree to one direction of the SDG's, but the impact of humans on environment is obvious and therefore further steps are taken. Nevertheless, these fifty years of SDG discussion concern several generations, spanning from expert-adults, students to children in the kindergarten. The younger generation even rises their voices against the systems in place, fuel the global and national discussions and actually lead to activities (De Moor et al 2020).

\section{With the eyes of children}

Children take a specific role in reaching the UN sustainable development goals. They are young and shape their future. Furthermore there is a big chance that the children's view on the SDG topics is almost not filtered by experiences, media influences and misaligned education. This viewpoint of "influencing preconceptions" depends on the age of children because of the cognitive development, their educational and living environment as well as parental guidance. According to the cognitive development steps of Piaget (1964) children's skills and abilities are age dependent. Therefore their view on the different topics may change as well as the ability of expressing thoughts to these complex topics differ.

Main stages of the cognitive development are the preoperational- (early childhood age), concrete operational(elementary age) and formal operational stage (adolescence) (Huitt \& Hummel 2003). In the preoperational stage the use of symbols, language and imagination is being developed. The concrete operational stage is characterized by the logical and systematic manipulation of symbols related to concrete, real-world objects. Operational thinking develops and egocentric thoughts decrease. In the formal operational stage symbols related to abstract concepts are logically used. At the same time a return to egocentric thoughts is observed (Huitt \& Hummel 2003).

For the observation of the children's view on SDG this means that even in the early childhood age analysis can be done with soft educational support, where "soft" means reduced influence on the person. Observations in the elementary age can make use of symbolic descriptions and manipulations.

Children may own an intuitive feeling about environmental changes and social injustices depending on their cognitive stage and knowledge. Studies indicate that children in an elementary stage have sophisticated perceptions of their environments and are able to identify how different variables, like forest, rivers, fauna, flora, human activities, influence each other (Pellier 2014). It is worth to explore their thoughts, especially for those longterm topics that will have direct influence on nowadays children, when they are adults. In addition, all the changes, that are needed for a sustainable ecosystem, need to be placed in an early childhood and elementary stage in order to be a natural part of the way of life of the adult.

Different ways of expression help to communicate thoughts. These ways cover drawing, speak out thoughts, telling stories, writing, handicrafts and similar art work. Especially when children are actively engaged in reflecting their behaviour in environment, they are able to communicate their thoughts with the help of the symbolic language of their drawings (Alerby 2000). These drawings require complementation with verbal explanations from children (Malchiodi 1998). Different studies confirm that drawings and their verbal complementation provide an efficient tool to receive insights into children thoughts (Pellier 2014, Guller \& Tokuc 2020).

Figure 2: Second sample of primary school statement

\author{
Freunde haben mir erzählt, dass es Wälder ohne Vögel gibt. Ich \\ möchte mir einen Wald ohne Vogelstimmen oder eine Welt ohne Wald gar nicht vorstellen. \\ Friends have told me that there are forests without birds. I would not like \\ to imagine a forest without bird calls or a world without forest.
}

Proceedings of the International Cartographic Association, 4, 2021.

30th International Cartographic Conference (ICC 2021), 14-18 December 2021, Florence, Italy. This contribution underwent

single-blind peer review based on submitted abstracts. https://doi.org/10.5194/ica-proc-4-48-2021 | @ Author(s) 2021. CC BY 4.0 License. 
The map is a specific form of drawing that is generally used to express spatial relations and conditions. Some study results indicate that children have landscape context-dependent perceptions for current and future environmental conditions (Pellier 2014). These perceptions can be influenced by awareness building for past environmental conditions, which is supported by spatial variables and their relationships, e.g. land use, land cover, topography or socio-economic variables. Spatial objects help to reference space and link to the direct environment. Children maps make use of these linkages and express children thoughts with simple and sometimes idiosyncratic symbolism. Examples of the biannual Barbara Petchenik map competition of the International Cartographic Association highlight these different forms of graphical expression of children maps (children maps 2019).

The stories of the section "kids in action" in the bookatlas "SDGs in action - a generations view" represent thoughts of children at different ages. The very early childhood ages ( $\sim 4$ years old) were guided by soft introduction into the topic and help with the expression by drawing. The later stages ( $~ 8$ to 9 years old) used a more intensive preoccupation with the selected topic and a free selection of expression mechanism, which included drawings, maps, narrative or handicraft. One observation in our few examples with soft education was that children trust in a positive development, pay close attention to changes in a near environment and often own fear of not being able to help shape it.

\section{The central role of maps}

There are different modes of expression to communicate spatial facts (Deane 2008). One may sing, tell a story, dance or draw an artwork. Stories make use of language, create images in our head and can be transmitted to a wide audience. The graphical mode of expression supports storytelling, enhances manifestation and clarification of our mental images and even allows detailed facts to be embedded. This is the point where maps come into play. It is the central role of maps to transmit spatial related facts and support its understanding, isn't it? Several methods of cartography deal with enhancement of spatial representation and the encoding of a set of information into graphical variables.

\section{Starting the production of the atlas "SDG's in action - a generation's view"}

Map production processes are evolving with new digital methods and technologies (Döllner et al 2018). The latest direction goes into full automatisation of map production, computer-proposed designs and the embedding of artificial intelligence. This industrial production approach for map production could on one hand enhance actuality of maps, but on the other lacks individual expression. A book atlas that is the host for the SDG stories of different generations need to be open for any kind of geospatial expression. For this very reason "SDG's in action - a generation's view" is designed as an atlas. The maps, statements, illustrations and biographies of contributors illustrate the range of perspectives on the SDGs and their motivations for establishing a sustainable world. The map or map-like representations are the core tool of

Figure 3: Starting page of the climate change chapter in the book atlas.
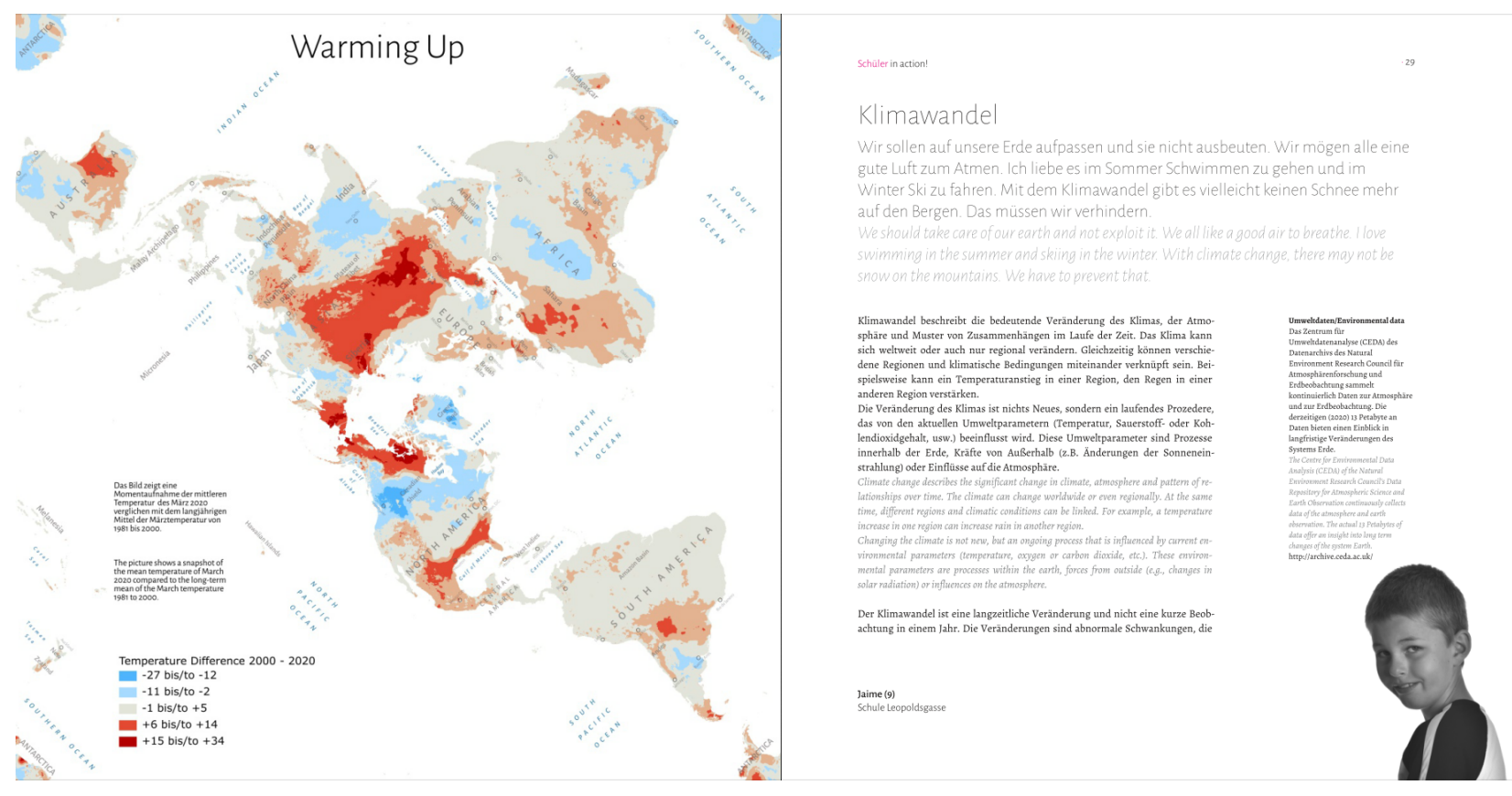
expression in order to bring the stories alive. The book atlas is created by common available free and open source software only, which emphasizes free access to map production for the general public.

The participants of the book atlas project are selected in various groups: very small children in the kindergarten, primary and secondary school, students before they access working life and experts at the climax of their career. A general questionnaire allows for a basic understanding of the participants, whereas an introduction to the SDG topic is done by the educational staff in the kindergarten and school. Depending on the quality of the educational staff, overwhelming examples and responses could be achieved. The selection of a SDG topic is done by participants on their own, depending on their affectedness (SDGgen 2019).

\section{Working with generations}

The different generations, kids, students and experts, required an adopted process of assistance. While an intensive exchange with educators was set up for the youngest generation, the students received multiple technical recursions for map production with a focus on the SDG as part of the thematic cartography lectures. Both included interviews and discussions.

\subsection{A standardized questionnaire}

For the generation of experts, the form of an interview was standardized by means of a questionnaire. Some interviews were conducted orally, others were received in writing.

The questionnaire is divided into three question areas: SDG's and me, general questions to SDG and a reflection part.

"SDG's and me" tries to query the main motivation to participate the book project and a main position to SDG.

The section "SDG in general" focuses on general positions and views, which concern small activities from the expert view, useful achievements and changes that are needed.

The "reflection" section questions the results of SDG actions in the expert's domain so far and the results of these developments in future.

We have observed that the responses of participating experts differ in their length and quality. Especially many of the written results without interaction lack of detail and can hardly be used as direct input to the chapters. This means that also for the expert group an interactive interview leads to more useful results.

\subsection{Stories and outstanding examples}

The stories of all participants up to date are impressive. For a large extend the map is the main media of expression. Selected concerns within a SDG topic were evaluated, available data from official sources collected and designed as a map. The kids in school received support from the ICA commission on map production, which was combined with a crash-course in cartography. Some of the classes were motivated to participate the ICA Barbara Petchenik contest. The outcome of the Kindergarten has been expressed as simple graphics, which were also part of the Barbara Petchenik contest. Therefore we can state that the ICA Barbara Petchenik contest is an important collection of maps which express how the younger generations experience our world (children maps 2019).

\section{Resume and perspectives}

The atlas "SDG's in action - a generation's view" is designed as bilingual book. From our perspective the different views on SDG coming from various generations and expressed as maps are a valuable documentation how we experience today's problems. As ICA commission of map production and geoinformation management we will try to support this initiative as good as possible for future editions. With this project and result, we have another evidence that the map is a very important tool for spatial expressiveness.

\section{References}

Alerby E (2000) A Way of Visualising Children's and Young People's Thoughts about the Environment: A study of drawings. Environ Educ Res 6: 205-222. https:/www.tandfonline.com/doi/abs/10.1080/1350462 0050076713

Barraza, Laura (1999) Children's Drawings About the Environment, Environmental Education Research, 5:1, 49-66, DOI: 10.1080/1350462990050103

Barrouillet, Pierre (2015) Theories of cognitive development: From Piaget to today, Developmental Review, Volume 38, 2015, Pages 1-12, ISSN 02732297

Bland, Derek (2012) Analysing children's drawings: applied imagination. International Journal of Research and Method in Education, 35(3), pp. 235-242. https://eprints.qut.edu.au/54844/

Children Maps (2019) Children Map Their World. Archive of the Barbara Petchenik children's map competition. [online] Available at: https://childrensmaps.library.carleton.ca/ [Accessed 18 Aug. 2021]. 
De Moor, J., Uba, K., Wahlström, M., Wennerhag, M., \& De Vydt, M. (2020). Protest for a future II: Composition, mobilization and motives of the participants in Fridays For Future climate protests on 20-27 September, 2019, in 19 cities around the world.

Deane, P. (2008). Multimodal spatial representation: On the semantic unity of over. In: From Perception to Meaning (pp. 235-284). De Gruyter Mouton.

Döllner, J., Jobst, M., \& Schmitz, P. (Eds.). (2018). Service-Oriented Mapping: Changing Paradigm in Map Production and Geoinformation Management. Springer.

Engström, K. (1973). United Nations Conference on the Human Environment, Stockholm, 1972.

Fisher, D. K.; Leon, N.; Fitzpatrick, A. J.; Jackson, R.; Greene, M. P. (2021) Play, Make, Know, Keep up, Watch, Dream, and Teach: A Kids-eye View of Climate Change;

https://ui.adsabs.harvard.edu/abs/2012AGUFMED23A0 733F/abstract

Fraisl, D., Campbell, J., See, L., Wehn, U., Wardlaw, J., Gold, M., Fritz, S. (2020). Mapping citizen science contributions to the UN sustainable development goals. Sustainability Science, 15(6), 1735-1751.

Guller, E. \& Tokuc, A. (2020). World from children's eyes: This is our World! International Journal of New Trends in Social Sciences. 4(1), 25-35. https://doi.org/10.18844/ijntss.v4i1.4890

Huitt, W., \& Hummel, J. (2003). Piaget's theory of cognitive development. Educational psychology interactive, 3 (2), 1-5.

Malchiodi CA (1998) Understanding children's drawings. London: Jessica Kingsley Publishers.

Pellier, Anne-Sophie; Wells, Jessie A.; Abram, Nicola K.; Gaveau, David; Meijaard, Erik (2014) Through the Eyes of Children: Perceptions of Environmental Change in Tropical Forests; Published: August 5, 2014; https://doi.org/10.1371/journal.pone.0103005

Piaget, J. (1964). Part I: Cognitive development in children: Piaget development and learning. Journal of research in science teaching, 2 (3), 176-186.

Sachs, J. D. (2012). From millennium development goals to sustainable development goals. The lancet, 379(9832), 2206-2211.

SDGgen (2019). SDGs in action - Generation Views. [online] Available at: http://sdggeneration.cartography.at/ [Accessed 14 Jun. 2021].

UNSD United Nations Statistics Division (2020). SDG Indicators. [online] Un.org. Available at: https://unstats.un.org/sdgs/indicators/database/

[Accessed 14 Jun. 2021]. 